\title{
Neurodevelopmental Outcome of Extremely Low Birth Weight Infants from the Vermont Oxford Network: 1998-2003
}

\author{
Charles E. Mercier ${ }^{a}$ Michael S. Dunn ${ }^{d}$ Karla R. Ferrellic Diantha B. Howard ${ }^{b}$ \\ Roger F. Soll ${ }^{a, c}$ and the Vermont Oxford Network ELBW Infant Follow-Up \\ Study Group
}

Departments of a Pediatrics and ${ }^{b}$ Biostatistics, University of Vermont, and ${ }^{~}$ Vermont Oxford Network, Burlington, Vt., USA; dSunnybrook Health Sciences Centre, Toronto, Ont., Canada

\section{Key Words}

Extremely low birth weight infant $\cdot$ Neurodevelopmental outcome $\cdot$ Severe disability $\cdot$ Vermont Oxford Network

\begin{abstract}
Background: Physicians and parents face significant uncertainties when making care decisions for extremely low birth weight (ELBW) infants. Many published estimates of death and developmental outcome are from well-funded university programs and may not reflect outcomes of infants from a variety of settings. The best estimates of the probabilities of death and severe disability combine local experience and published data. Objective: To describe the neurodevelopmental outcome of ELBW infants from centers of the ELBW Infant Follow-Up Group of the Vermont Oxford Network (VON) and to identify characteristics associated with severe disability. Methods: Predefined measures of living situation, health and developmental outcome were collected at 18-24 months' corrected age for infants born from July 1, 1998 to December 31, 2003 with birth weights of 401-1,000 $\mathrm{g}$ at 33 North American VON centers. Logistic regression was used to identify characteristics associated with severe disability. Results: 6,198 ELBW infants were born and survived until hospital discharge; by the time of follow-up, 88 infants (1.4\%) had died. Of the remaining 6,110 infants, 3,567 (58.4\%) were
\end{abstract}

evaluated. Severe disability occurred in $34 \%$ of the assessed infants. Multivariate logistic regression suggested cystic periventricular leukomalacia, congenital malformation and severe intraventricular hemorrhage were the characteristics most highly associated with severe disability. There were marked variations among the follow-up clinics in the attrition rate. Conclusion: ELBW infants completing evaluation were at a high risk for severe disability. There are considerable differences among participating centers in attrition at follow-up. Further resources will be needed to study the effect of follow-up care for this group of infants.

Copyright $\odot 2009$ S. Karger AG, Basel

\section{Introduction}

The Vermont Oxford Network (VON) is a non-profit voluntary collaboration of university affiliated and university non-affiliated hospital centers with neonatal intensive care units (NICUs) focused on improving the quality and safety of medical care for newborn infants and their families. The network operates a database in which participating centers collect basic demographic and clinical outcome data until hospital discharge for infants weighing between 401 and 1,500 $\mathrm{g}$ at birth. In 2003, over 440 centers participated in VON enrolling over

\section{KARGER}

(ㄷ) 2009 S. Karger AG, Basel

Fax +41613061234 E-Mail karger@karger.ch www.karger.com
Accessible online at: www.karger.com/neo
Charles E. Mercier, MD

Smith 578 MCHV Campus, Fletcher Allen Health Care

111 Colchester Avenue

Burlington, VT 05401 (USA)

Tel. +1 802847 2495, Fax +1 802847 5225, E-Mail charles.mercier@vtmednet.org 
34,500 very low birth weight (VLBW) infants in the database, representing about $65 \%$ of all VLBW infants born in the United States. Published reports from VON describe trends in clinical practice, mortality and hospitalbased outcomes for VLBW infants [1-3].

Among VLBW infants, those born weighing less than $1,000 \mathrm{~g}$ have the highest rates of mortality and morbidity [3]. Outcome reports from funded research at university affiliated institutions within the United States $[4,5]$ and national health registries [6-10] outside of North America suggest these extremely low birth weight (ELBW) infants are at significant risk for poor health and neurodevelopmental outcomes at 2 years' corrected age.

To report on outcomes for ELBW infants receiving care at centers participating in VON, $36 \mathrm{NICU}$-associated follow-up clinics volunteered to collect data on health and neurodevelopment at 18-24 months' corrected age. All follow-up clinics routinely assessed ELBW infants though 2 years of corrected age, used the Bayley Scales of Infant Development-II (BSID-II) [11] and obtained local institutional review board approval for the study. Of the 36 participating clinics, 33 were associated with NICUs in North America (31 in the USA, 2 in Canada), 1 was in Europe and 2 were in Asia. This report describes the findings from the 33 North American clinics. The outcomes for ELBW infants from one of the Asian clinics are reported elsewhere [12].

\section{Methods}

Data on health and developmental outcomes were collected for surviving ELBW infants (birth weight of 401-1,000 g) born from 1998 through 2004 at 33 centers participating in VON. Participating centers had associated follow-up clinics which routinely followed surviving ELBW infants between 18 and 24 months of corrected age for a comprehensive assessment. Routines for contacting parents or guardians of infants, as well as for scheduling infant follow-up visits, were performed according to local procedures at the follow-up clinic. Parental informed consent for infant evaluation, data collection and reporting was sought according to the specifications of each center's institutional review board.

Outcome measures at 18-24 months' corrected age included assessment of the home living situation, health status and developmental status of the infants. Measures were reported using standardized data collection tools; each data item was defined in the ELBW Infant Follow-Up Manual of Operations [13]. In accordance with the Federal Health Insurance Portability and Accountability Act, all data were de-identified as of January 1, 2002.

The assessment of the home living situation included information regarding with whom the child resided (parent/family member, foster care, chronic care facility), the type of social support found in the home (single parent, single parent extended family, two parent, two parent extended family, institutional) and the education level of the primary care giver (grade 8 or less, some high school, high school graduate, some college/university, college/university graduate).

The assessment of the health outcomes included information regarding whether the child needed medical support after hospital discharge and, if so, the type of medical support provided (tracheostomy, ventilator, oxygen, gastrostomy, nasogastric feeds, apnea or cardio-respiratory monitor); whether there were subsequent re-hospitalizations and, if so, the number of admissions for each category of re-hospitalization (respiratory illness, nutrition or failure to thrive, seizure disorder, shunt complications or infections); and whether there were surgical procedures performed after discharge, and, if so, the type of surgical procedure. Re-hospitalizations were defined as re-admissions to the hospital requiring an overnight stay. Visits to hospital-based specialty clinics and the emergency room were excluded. Surgical procedures did not necessarily require re-hospitalization. The infant's weight and head circumference were also measured at follow-up; subnormal growth was defined as a weight or head circumference measuring less than the 10th percentile for corrected age using the gender-specific growth charts for the United States [14].

The assessment of the developmental outcomes included information from the neurological and developmental evaluations. The neurological evaluation included assessment of vision (blindness in one or both eyes), hearing (corrective hearing aids for one or both ears) and muscle tone (hypotonia, hypertonia). Whether the infant could walk 10 steps independently and, if not, whether the infant could walk 10 steps with support was reported, as was whether the infant had cerebral palsy. Cerebral palsy (quadriplegia, hemiplegia, diplegia) was defined as a nonprogressive, non-transient central nervous system disorder characterized by abnormal control of movement or posture, or both, not due to mental retardation, meningomyelocele or other spinal cord lesions. The developmental evaluation was performed using the BSID-II [11]. Scores, corrected for the degree of prematurity, were collected for the Mental Development Index (MDI) and the Psychomotor Development Index (PDI). Scores from the Behavior Rating Scale were not collected. Scores of $100 \pm 15$ represented the mean \pm 1 standard deviation. A score of less than 70 was interpreted to represent significantly delayed performance.

Severe disability was defined by the presence of one or more of the following: bilateral blindness, hearing impairment requiring amplification, inability to walk 10 steps with support, cerebral palsy, or an MDI or PDI score of less than 70. The definition of severe disability was modified from the work of Schmidt et al. [15].

\section{Statistical Analysis}

Statistical analyses were performed using SAS statistical software version 9.1 (SAS Institute, Cary, N.C., USA).

Maternal and neonatal characteristics, NICU interventions and NICU outcomes as defined in the VON Database Manual of Operations [16] included antenatal steroids, mode of delivery, multiple gestation, inborn/outborn status, race, gender, birth weight, gestational age, low 5-min Apgar score, delivery room cardiac compressions, congenital malformation, small for gestational age status (birth weight less than the 10th percentile for age 
Fig. 1. Outcome status at 2 years' corrected age for the 8,636 live born ELBW infants at the 33 participating North American VON centers from July 1, 1998 to December 31, 2003.

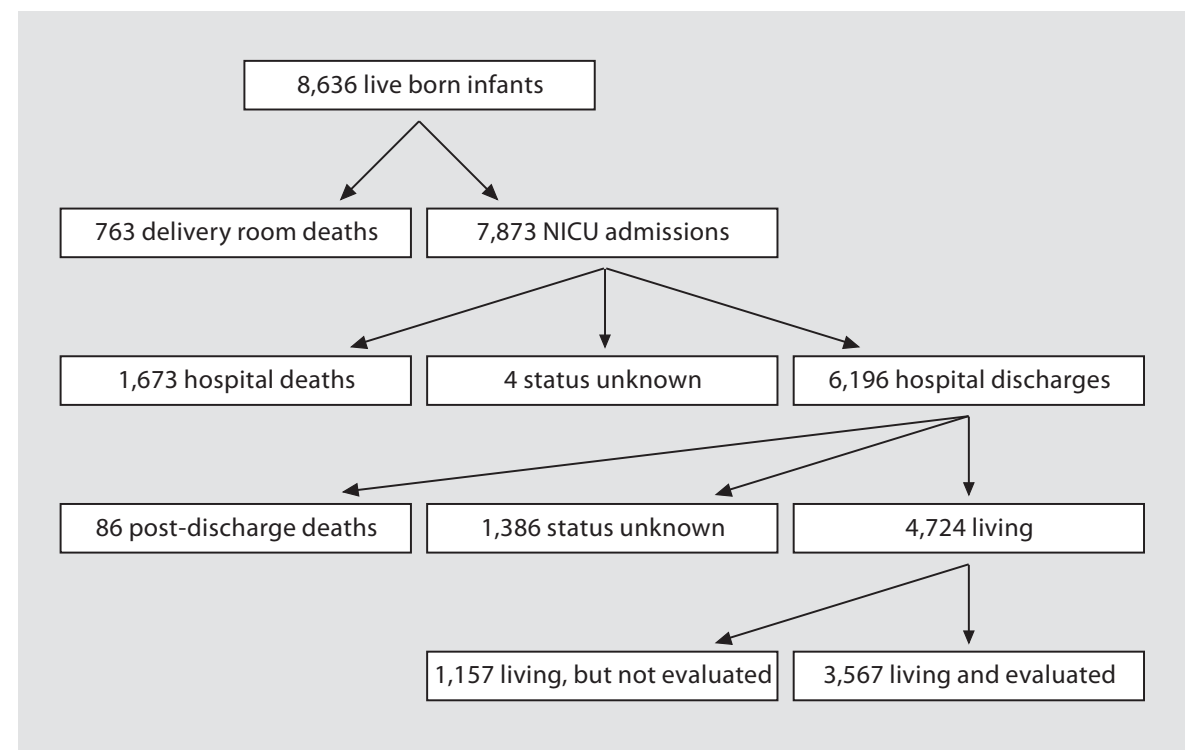

and limited to infants $<30$ weeks gestation at birth), early bacterial sepsis, late bacterial sepsis, oxygen at 36 weeks postmenstrual age, postnatal steroids for chronic lung disease, severe (grade 3-4) intraventricular hemorrhage, cystic periventricular leukomalacia, severe (stage 3-4) retinopathy of prematurity (ROP) and/ or ROP surgery. Home living situation characteristics, as defined in the VONELBW Infant Follow-Up Project Manual of Operations [13], included single parent and primary caretaker educational level. The network center follow-up rate was defined as the followup rate of infants known to have survived until hospital discharge and not reported as dead by the 18-24 months' corrected age follow-up visit.

Characteristics of infants seen in follow-up (evaluated infants) and infants not seen in follow-up (not evaluated) were compared using a $\chi^{2}$ test for categorical variables and Student's $t$ test for birth weight and gestational age. Kendall's tau was used to test the relationship between birth weight stratum and death or disability rates. Kendall's tau was also used in secondary analysis to assess trends over time for infant characteristics and disability rates.

Univariate logistic regressions were used to identify associations of maternal and neonatal characteristics, NICU interventions, NICU outcomes, home living situation characteristics and network center follow-up rates, all expressed in dichotomous form, with severe disability. In dichotomous form, the network center follow-up rate was expressed as a rate greater than or equal to $80 \%$ over all the years of the study. Results of the univariate logistic regressions were expressed as odds ratios (ORs) and 95\% confidence intervals (CIs).

Stepwise multivariate logistic regression was used to determine which of the above characteristics best predicted severe disability. All variables significant at the $\mathrm{p}<0.001$ level were then entered into a model using SAS Proc Genmod, to calculate adjusted ORs and 95\% CIs. All significance tests associated with characteristics in the model reflect adjustment for the clustering of infants within centers.

Neurodevelopmental Outcome of Extremely Low Birth Weight Infants

\section{Results}

Participating centers had a median of 24 NICU beds (range 12-52) and a median of 54 infant admissions (range 17-110) with a birth weight less than 1,000 g. Twenty-six (79\%) of the centers had housestaff participating in direct patient care in the NICU as a part of training. Centers were self-classified as government (federal or non-federal, $\mathrm{n}=3$ ); non-government, not-for-profit $(n=28)$; investor owned, for profit $(n=2)$.

A total of 8,636 ELBW infants born from July 1, 1998 to December 31, 2003 were reported. Of these, $763(8.8 \%)$ died in the delivery room and 7,873 (91.2\%) were admitted to the NICU. Of the infants admitted to the NICU, 1,673 (21.2\%) died before hospital discharge, 6,196 (78.7\%) survived until hospital discharge and the status of 4 infants was unknown when data collection was closed at 1 year of age. By the time of follow-up, 88 infants (1.4\%) were known to have died (86 infants post-discharge and 2 of the 4 infants for whom status was unknown at 1 year of age). Of the remaining 6,110 infants, 3,567 of the infants (58.4\%) were evaluated and 2,543 (41.6\%) were not evaluated. Of the 2,543 infants not evaluated, 1,157 (44.5\%) were known to be alive, but the status of the remaining 1,386 infants (54.5\%) was unknown (fig. 1).

Evaluated infants were assessed at a mean corrected age of $20.6 \pm 2.1$ months. The follow-up rate varied among centers; the median center follow-up rate over the 6-year study period was $57.0 \%$ (range $12.5-94.9 \%)$. Of the 3,567 evaluated infants, $1,187(33.2 \%)$ were evaluated at 
Table 1. Characteristics of known surviving ELBW infants evaluated and not evaluated

\begin{tabular}{|c|c|c|c|c|c|}
\hline Characteristic & \multicolumn{2}{|c|}{ Evaluated $(\mathrm{n}=3,567)$} & \multicolumn{2}{|c|}{ Not evaluated $^{1}(\mathrm{n}=2,543)$} & $\mathrm{p}$ \\
\hline \multicolumn{6}{|l|}{ Maternal } \\
\hline Prenatal care & $3,469 / 3,567$ & $97.3 \%$ & $2,375 / 2,538$ & $93.6 \%$ & * \\
\hline Any antenatal steroid & $2,932 / 3,564$ & $82.3 \%$ & $2,034 / 2,532$ & $80.3 \%$ & \\
\hline Vaginal delivery & $1,209 / 3,567$ & $33.8 \%$ & $842 / 2,541$ & $33.1 \%$ & \\
\hline Multiple birth & $1,062 / 3,566$ & $29.85 \%$ & $594 / 2,543$ & $23.4 \%$ & $*$ \\
\hline Inborn & $3,049 / 3,567$ & $85.5 \%$ & $1,955 / 2,543$ & $76.9 \%$ & $*$ \\
\hline \multicolumn{6}{|l|}{ Infant } \\
\hline Birth weight & $777 \pm 140$ & & $791 \pm 142$ & & $*$ \\
\hline Gestational age & $26.4 \pm 2.0$ & & $26.6 \pm 2.1$ & & $*$ \\
\hline SGA status & $715 / 3,566$ & $20.1 \%$ & $552 / 2,543$ & $21.7 \%$ & \\
\hline Male & $1,748 / 3,567$ & $49.0 \%$ & $1,240 / 2,542$ & $48.8 \%$ & \\
\hline Non-white & $1,293 / 3,566$ & $36.3 \%$ & $1,081 / 2,542$ & $42.5 \%$ & $*$ \\
\hline Birth defects & $65 / 3,567$ & $1.8 \%$ & $81 / 2,543$ & $3.2 \%$ & * \\
\hline \multicolumn{6}{|l|}{ Delivery room } \\
\hline Intubation & $2,974 / 3,567$ & $83.4 \%$ & $2,051 / 2,540$ & $80.8 \%$ & $*$ \\
\hline Cardiac compressions & $247 / 3,567$ & $6.9 \%$ & $189 / 2,539$ & $7.4 \%$ & \\
\hline \multicolumn{6}{|l|}{ Neonatal course } \\
\hline Received surfactant & $3,025 / 3,567$ & $84.8 \%$ & $2,198 / 2,539$ & $86.5 \%$ & \\
\hline Pneumothorax & $210 / 3,567$ & $5.9 \%$ & $190 / 2,542$ & $7.5 \%$ & \\
\hline Received HFOV & $1,597 / 3,566$ & $44.8 \%$ & $1,066 / 2,543$ & $41.9 \%$ & \\
\hline Steroids for CLD & $1,526 / 3,567$ & $42.8 \%$ & $989 / 2,543$ & $38.9 \%$ & * \\
\hline Oxygen at 36 weeks & $1,597 / 3,078$ & $51.6 \%$ & $1,021 / 2,122$ & $48.1 \%$ & 0.015 \\
\hline Treatment for PDA & $2,353 / 3,567$ & $66.0 \%$ & $1,532 / 2,542$ & $60.3 \%$ & * \\
\hline Necrotizing enterocolitis & $257 / 3,567$ & $7.2 \%$ & $209 / 2,542$ & $8.2 \%$ & 0.14 \\
\hline Early-onset bacterial sepsis & $71 / 3,566$ & $2.0 \%$ & $46 / 2,541$ & $1.8 \%$ & \\
\hline Late-onset bacterial sepsis & $1,177 / 3,566$ & $33.0 \%$ & $798 / 2,537$ & $31.5 \%$ & 0.20 \\
\hline Severe IVH & $303 / 3,566$ & $8.5 \%$ & $236 / 2,537$ & $9.3 \%$ & 0.26 \\
\hline Cystic PVL & $139 / 3,556$ & $3.9 \%$ & $114 / 2,531$ & $4.5 \%$ & 0.22 \\
\hline Severe ROP stage 3-4 & $701 / 3,353$ & $20.9 \%$ & $451 / 2,287$ & $19.7 \%$ & 0.28 \\
\hline
\end{tabular}

centers with a follow-up rate of greater than or equal to $80 \%$ for the entire study period. The all-center follow-up rate did not differ from year to year (range 56.5-59.5\%). The follow-up rate did not vary with the mean number of NICU beds, the mean number of NICU admissions with a birth weight less than $1,000 \mathrm{~g}$ or the participation of housestaff in NICU care.

Mortality by the time of follow-up differed among centers. The median center mortality rate over the 6-year study period was $28.0 \%$ (range: $16.7-51.7 \%$ ). The all-center mortality rate for ELBW infants over the study period did not differ from year to year (range 28.2-30.7\%).

The maternal and neonatal characteristics of infants evaluated and of infants not evaluated are shown in table 1. Mothers of evaluated infants were more likely to have received prenatal care $(97.3$ vs. $93.6 \%, \mathrm{p}<0.01)$, but they were not more likely to have received antenatal steroids (82.3 vs. $80.3 \%)$. Evaluated infants were more likely to have been inborn ( 85.5 vs. $76.9 \%, \mathrm{p}<0.01)$ and of a multiple gestation (29.8 vs. $23.4 \%, \mathrm{p}<0.01)$. Evaluated infants were born earlier ( 26.4 vs. 26.6 weeks, $\mathrm{p}<0.01$ ) and weighed less ( $777 \mathrm{vs.} 791 \mathrm{~g}, \mathrm{p}<0.01$ ) than infants who were not evaluated. Evaluated infants were less likely to be non-white ( 36.3 vs. $42.5 \%, \mathrm{p}<0.01)$ and less likely to have a birth defect ( 1.8 vs. $3.2 \%, \mathrm{p}<0.01)$.

NICU interventions and outcomes of infants evaluated and of infants not evaluated are also shown in table 1 . Compared to evaluated infants, infants not evaluated were no more likely to have had necrotizing enterocolitis (7.2 vs. $8.2 \%, p=0.14$ ), late-onset bacterial sepsis (33.0 vs. 
Table 2. Sensory, neurological, functional and developmental morbidities in evaluated ELBW infants ${ }^{1}$

\begin{tabular}{lrc}
\hline Morbidity & Infants, $\mathrm{n}$ & Infants, \% \\
\hline Bilateral blindness & $41 / 3,537$ & $1.2 \%$ \\
Hearing loss with amplification & $62 / 3,240$ & $1.9 \%$ \\
Unable to walk 10 steps with support & $157 / 3,565$ & $4.4 \%$ \\
Cerebral palsy & $301 / 3,563$ & $8.5 \%$ \\
Bayley II MDI <70 & $721 / 3,229$ & $22.3 \%$ \\
Bayley II PDI <70 & $615 / 2,993$ & $20.6 \%$ \\
\hline
\end{tabular}

${ }^{1}$ An infant could have more than 1 morbidity.

$31.5 \%, p=0.20)$, severe intraventricular hemorrhage (8.5 vs. $9.3 \%, \mathrm{p}=0.26$ ), periventricular leukomalacia (3.9 vs. $4.5 \%, \mathrm{p}=0.22)$ or severe ROP ( 20.9 vs. $19.7 \%, \mathrm{p}=0.28$ ). However, evaluated infants were more likely to have received steroids for chronic lung disease ( 42.8 vs. $38.9 \%$, $\mathrm{p}<0.01)$, received treatment for a patent ductus arteriosus $(66.0$ vs. $60.3 \%, \mathrm{p}<0.01)$ and tended to have received oxygen at 36 weeks postmenstrual age (51.6 vs. $48.1 \%$, $\mathrm{p}=0.015)$.

At the time of follow-up, nearly all infants (97.3\%) were reported to be living in a home. Most infants (76.7\%) lived with 2 parents. Most primary care givers (65.5\%) for the infants had some college education or more; $38.9 \%$ of primary care givers were college graduates.

After hospital discharge, 982 infants (27.5\%) continued to receive oxygen supplementation, $99(2.8 \%)$ received nasogastric feeds and 196 (5.5\%) had a gastrostomy tube. Between hospital discharge and follow-up, 1,418 of the infants $(40.1 \%)$ were re-hospitalized at least once; for all of the infants, respiratory illness was the most frequently reported reason for re-hospitalization (27.1\%). Surgical procedures after hospital discharge were performed for 1,127 of all of the infants (31.7\%), with hernia repair the most frequently reported procedure (9.1\%).

At the time of the follow-up visit, 1,617 infants (46.0\%) weighed less than the 10th percentile for corrected age and 1,100 infants (31.3\%) weighed less than the 3rd percentile for corrected age. Also at the time of the follow-up visit, 762 infants (21.8\%) were reported as having a head circumference smaller than the 10th percentile for corrected age and 397 infants (11.3\%) had a head circumference smaller than the 3rd percentile for corrected age. Overall, 563 infants (16.2\%) had both a weight and head circumference less than the 10th percentile; 263 infants
(7.5\%) had a weight and head circumference less than the 3rd percentile at follow-up.

Sensory, neurological, functional and developmental morbidities in evaluated ELBW infants are shown in table 2 . There were 41 infants (1.2\%) reported to be blind in both eyes. Corrective prescription eyewear was reported for 316 infants (10.2\%). There were 62 infants $(1.9 \%)$ reported as wearing an amplification device for hearing loss. Hearing impairment or loss was reported for 151 infants (4.8\%).

On neurological examination, 301 infants $(8.5 \%)$ were assessed as having cerebral palsy. Of infants assessed with cerebral palsy, 104 (34.7\%) were noted to be quadriplegic, 68 (22.7\%) were hemiplegic and 128 (42.7\%) were diplegic. Of the infants not diagnosed as having cerebral palsy, 507 (15.6\%) were reported to have abnormalities in muscle tone. Of infants with muscle tone abnormalities, hypotonia was most frequently noted (76.1\%). Assessment of gross motor milestones showed 373 infants (10.5\%) were unable to walk 10 steps independently. Of infants unable to walk 10 steps independently, 157 (41.6\%) were unable to walk 10 steps with support. Of these 157 infants, the majority (78.3\%) had been assessed as having cerebral palsy.

At the developmental assessment, the median BSID-II MDI for evaluated infants was 87 and the interquartile range was $71-101$. Overall, 721 evaluated infants $(22.3 \%)$ had an MDI $<70$. The median BSID-II PDI for evaluated infants was 90 and the interquartile range was $74-100$. Overall, 615 evaluated infants $(20.6 \%)$ had a PDI $<70$.

There were 1,136 infants (34.2\%) assessed as severely disabled. Of the infants assessed as severely disabled, 854 infants (75.2\%) had 1 morbidity contributing to their severe disability and 283 (24.8\%) had multiple morbidities. The relative contribution of individual morbidities (e.g. cerebral palsy) to severe disability did not change over the study period. At clinics with a follow-up rate of greater than or equal to $80 \%$ for the entire study period, the rate of severe disability was $36.7 \%$. Of the infants assessed at these clinics, $9.4 \%$ had cerebral palsy, $21.3 \%$ had a BSIDII MDI $<70$ and $20.7 \%$ had a BSID-II PDI $<70$.

The results of univariate logistic regression models are shown in figure 2 . In the univariate model, the factors associated with an increased risk of severe disability include cystic periventricular leukomalacia, severe intraventricular hemorrhage, early bacterial sepsis, congenital malformation, severe ROP and/or ROP surgery, 5-min Apgar score less than or equal to 3, gestational age less than 25 weeks, postnatal steroids for chronic lung disease, oxygen at 36 weeks postmenstrual age, delivery 


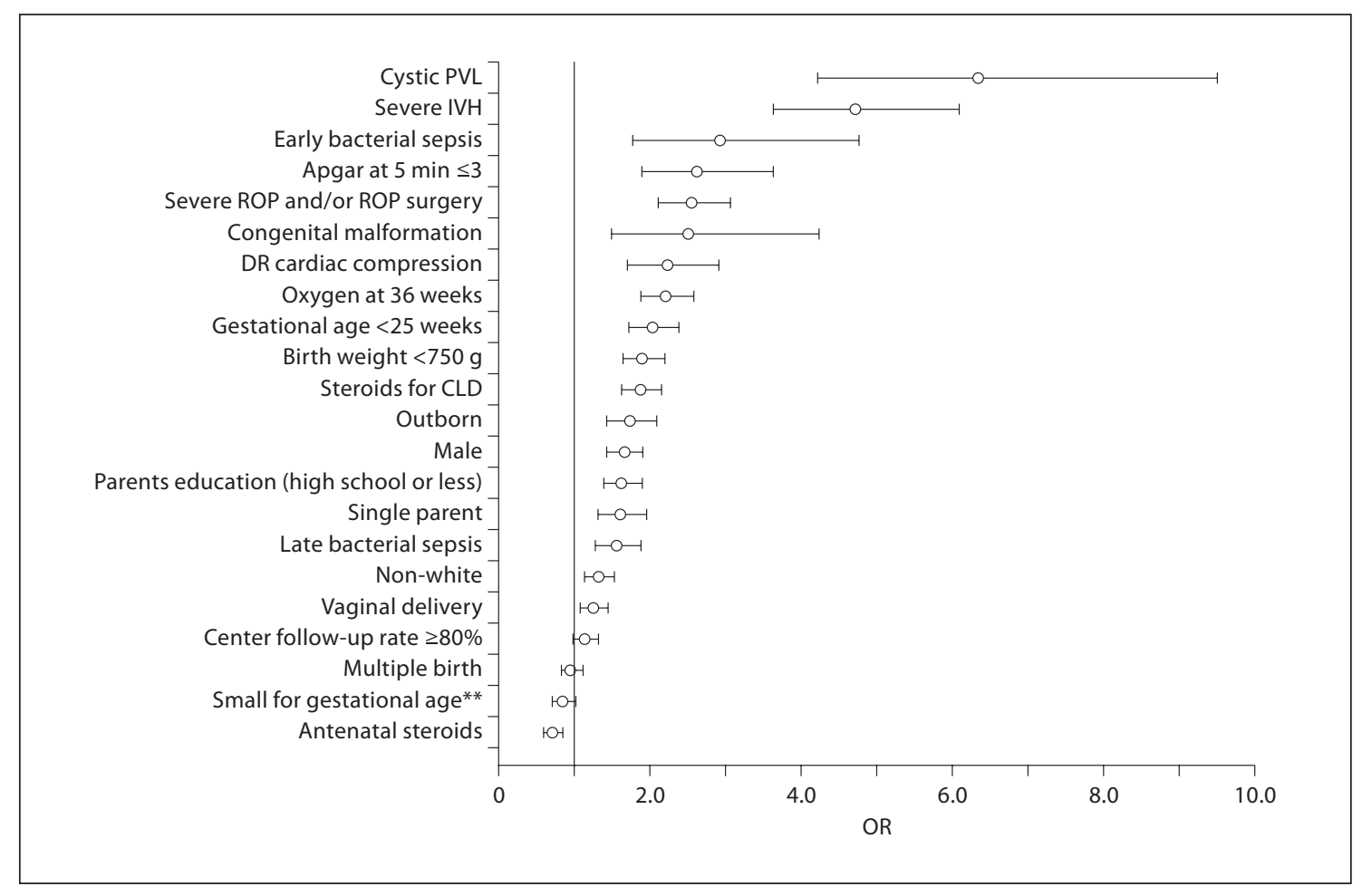

Fig. 2. Risk factors for severe disability (OR and 95\% CI). Antenatal steroids indicate any corticosteroid administered to the mother during pregnancy at any time before delivery; severe ROP indicates stage 3 or 4 disease on any indirect ophthalmologic exam performed; congenital malformation indicates a birth defect considered lethal or life-threatening; severe intraventricular hemorrhage (IVH) indicates a grade 3 or 4 IVH on any cranial ultrasound performed before day 28 of life. PVL $=$ Periventricular leukomalacia; DR = delivery room; $\mathrm{CLD}=$ chronic lung disease. ${ }^{*}$ Birth weight less than the 10 th percentile for age and limited to infants $<30$ weeks gestation at birth.

room cardiac compressions, birth weight less than $750 \mathrm{~g}$, outborn status, primary caregiver education of high school or less, single parent, male gender, non-white or Hispanic race, vaginal delivery, and late bacterial sepsis. Neither small for gestational age status, multiple birth, nor the network center follow-up rate was associated with an increased or decreased risk of severe disability. Use of antenatal steroids was associated with a decreased risk of severe disability.

The results of a multivariate logistic regression model are shown in table 3. Adjusting for the clustering of infants within centers, characteristics associated with an increased risk of severe disability were cystic periventricular leukomalacia, congenital malformation, severe intraventricular hemorrhage, Apgar at $5 \mathrm{~min}$ less than or equal to 3, severe ROP or surgery for ROP, oxygen at 36 weeks postmenstrual age, caregiver education level of high school or less, male gender, delivery room cardiac compressions, and decreasing birth weight per 100-gram
Table 3. Multivariate logistic regression-adjusted risk factors for severe disability ${ }^{1}$

\begin{tabular}{lccc}
\hline Characteristic & OR & \multicolumn{2}{c}{$95 \%$ CI } \\
\hline Cystic PVL & 5.56 & 3.76 & 8.22 \\
Congenital malformation & 3.15 & 1.55 & 6.40 \\
Severe IVH & 3.05 & 2.45 & 3.79 \\
Apgar at 5 min $\leq 3$ & 2.06 & 1.45 & 2.93 \\
Severe ROP or surgery for ROP & 1.59 & 1.23 & 2.04 \\
Oxygen at 36 weeks & 1.53 & 1.28 & 1.84 \\
Care giver education high school or less & 1.49 & 1.27 & 1.75 \\
Male gender & 1.82 & 1.50 & 2.22 \\
Delivery room cardiac compressions & 1.83 & 1.49 & 2.25 \\
Birth weight per decrease of 100-gram interval & 1.26 & 1.17 & 1.36 \\
\end{tabular}

$\mathrm{p}<0.001$ for all variables. Max. rescaled $\mathrm{r}^{2}=0.21$. PVL $=$ Periventricular leukomalacia; IVH = intraventricular hemorrhage.

${ }^{1}$ Adjusted for clustering of infants within centers and other factors in the model. 
Table 4. Death or severe disability by 100 -gram birth weight interval for infants born weighing 401-1,000 g

\begin{tabular}{lrrcc}
\hline $\begin{array}{l}\text { Birth weight } \\
\text { g }\end{array}$ & Born & Died & $\begin{array}{l}\text { Of known living infants, } \\
\text { those assessed }\end{array}$ & $\begin{array}{l}\text { Of assessed infants, } \\
\text { those with severe } \\
\text { disability }\end{array}$ \\
\hline $401-500$ & 719 & $549(76.4)$ & $96 / 131(73.3)$ & $57 / 96(59.4)$ \\
$501-600$ & 1,331 & $721(54.2)$ & $342 / 493(69.6)$ & $160 / 342(46.8)$ \\
$601-700$ & 1,557 & $519(33.3)$ & $582 / 828(70.3)$ & $236 / 582(40.6)$ \\
$701-800$ & 1,723 & $362(21.0)$ & $772 / 1,066(72.4)$ & $277 / 772(35.9)$ \\
$801-900$ & 1,637 & $202(12.3)$ & $771 / 1,098(70.2)$ & $207 / 771(26.9)$ \\
$901-1,000$ & 1,669 & $171(10.2)$ & $758 / 1,108(68.4)$ & $199 / 758(26.3)$ \\
\hline Total & 8,636 & $2,524(29.2)$ & $3,321 / 4,724(70.3)$ & $1,136 / 3,321(34.2)$ \\
\hline
\end{tabular}

Figures in parentheses represent percentages.

Table 5. Death or severe disability by week of gestational age at birth interval for infants born $<23^{+0}$ to $25^{+6}$ weeks gestation

\begin{tabular}{lrccc}
\hline $\begin{array}{l}\text { Gestational age } \\
\text { weeks }\end{array}$ & Born & Died & $\begin{array}{l}\text { Of known living infants, } \\
\text { those assessed }\end{array}$ & $\begin{array}{l}\text { Of assessed infants, } \\
\text { those with severe disability }\end{array}$ \\
\hline$<23^{+0}$ & 528 & $504(95.5)$ & $15 / 21(71.4)$ & $11 / 15(73.3)$ \\
$23^{+0}-23^{+6}$ & 916 & $567(61.9)$ & $214 / 298(71.8)$ & $112 / 214(52.3)$ \\
$24^{+0}-24^{+6}$ & 1,452 & $535(36.8)$ & $531 / 737(72.0)$ & $234 / 531(44.1)$ \\
$25^{+0}-25^{+6}$ & 1,581 & $371(23.5)$ & $698 / 965(72.3)$ & $261 / 968(27.0)$ \\
\hline Total & 4,477 & $1,977(44.2)$ & $1,458 / 2,021(72.1)$ & $618 / 1,728(35.8)$ \\
\hline
\end{tabular}

Figures in parentheses represent percentages.

interval. However, these characteristics predicted only $21 \%$ ( $\mathrm{r}^{2}$ coefficient) of the variation in severe disability among surviving ELBW infants.

The rates of death and severe disability by 100 -gram birth weight interval category $(401-1,000 \mathrm{~g})$ are shown in table 4 , and by gestational age ( $<23$ weeks to $25^{+6}$ weeks) in table 5. More infants at lower birth weight died ( $\mathrm{p}=$ 0.01). For surviving ELBW infants, every 100-gram decrease in birth weight increased the risk of severe disability by $31 \%$ (OR $1.31 ; 95 \%$ CI 1.24, 1.38). More infants at lower gestational ages died $(\mathrm{p}<0.01)$. For surviving infants, every week decrease in gestational age increased the risk of severe disability by $35 \%$ (OR 1.35; 95\% CI 1.18, 1.54).

The overall risk of death by the 18-24 months' corrected age follow-up visit for all live-born ELBW infants was $29.2 \%$. The overall risk of severe disability by the 18 24 months' corrected age follow-up visit for all surviving and evaluated ELBW infants was $34.2 \%$. For infants born at centers with a follow-up rate of greater than or equal to $80 \%$, the overall risk of death was $33 \%$ and the overall risk of severe disability was $36.7 \%$.

The rate of severe disability for each year of the study period is shown in figure 3 . The rate of severe disability remained steady over the entire study period $(-4.3 \%$; $95 \%$ CI $-11.5 \%, 2.7 \%)$, as did the rate of cerebral palsy $(-2.8 \%$; $95 \%$ CI $-7.1 \%, 1.5 \%)$. During this same time, the mortality rate did not change $(0.9 \%$; $95 \%$ CI $-3.2 \%, 5.0 \%)$, but the follow-up rate increased (9.0\%; 95\% CI 3.0\%, 15.1\%). There were decreases in the number of inborn infants $(-8.7 \%$; $95 \%$ CI $-13.2 \%,-4.3 \%)$, the rate of steroid use for chronic lung disease $(-35.8 \%$; $95 \%$ CI $-42.4 \%,-29.3 \%)$ and the rate of mothers with an educational level of high school or less $(-8.0 \%$; 95\% CI $-15.4 \%,-0.9 \%)$. There was an increase in the rate of oxygen use at 36 weeks postmenstrual age over the study period $(12.1 \%$; $95 \%$ CI $4.6 \%$, $19.6 \%)$. 


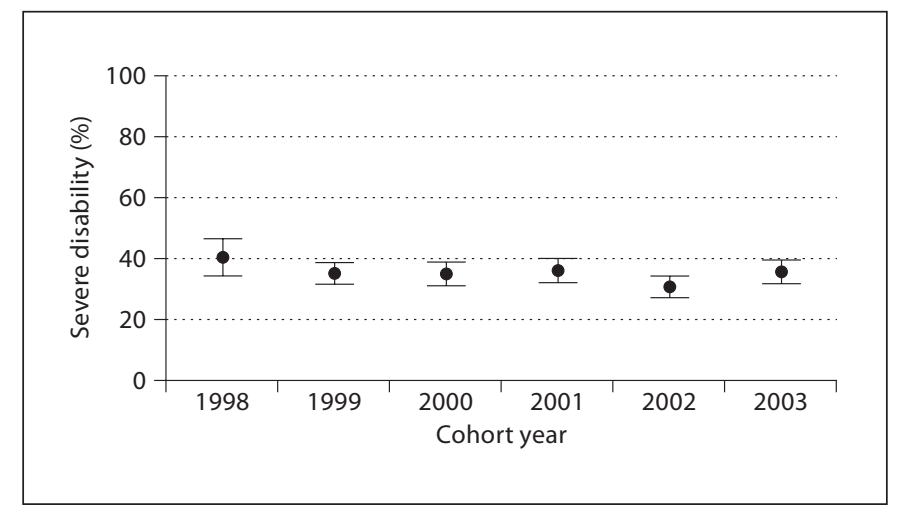

Fig. 3. Observed rates and $95 \%$ CI for severe disability by cohort year.

\section{Discussion}

The VON ELBW Infant Follow-Up Study Group is a unique collaboration of NICU-associated follow-up clinics with investigators giving their time voluntarily and clinics operating without research-funded compliancedependent financial support. The wide variation of center-based follow-up rates in this study likely reflects the complexity and burden of operating a follow-up program and conducting standardized follow-up assessment within the context of a local and regional health care system.

Other recent multi-center reports of ELBW infant outcomes have achieved more uniform follow-up rates [410]. When analysis of the population of ELBW infants in this study was restricted to a subgroup of clinics with follow-up rates greater than $80 \%$, the overall risk of severe disability was similar to the all center severe disability risk.

Our observation of severe disability risk is less than risk estimates previously published by the NICHD [4]. It is possible that the difference in risk estimate is because of differences in the population of families described in these 2 reports. The caregivers of evaluated infants in our study were generally 2 parents with 16 or more years of school. In contrast, $49 \%$ of families of infants in the NICHD study were single mothers, $28 \%$ of whom were not high school graduates. Such differences in populations of families highlight why, in providing information to parents, physicians should consider both outcome data reported in current literature and outcome data based on local experience [17-19].

It is unclear how a follow-up rate affects the true incidence of severe disability. Several reports on attrition in follow-up programs suggest infants with serious developmental delays or disabilities are more likely to dropout of follow-up [20-24]. On the other hand, Castro et al. [25] found that ELBW infants compliant with follow-up were more likely to have worse developmental outcome compared to infants who are lost to follow-up. Although it is likely external support will be necessary to improve attrition, the VON Study Group has the potential for performing large-scale research and quality-of-care-based projects in follow-up outcomes.

Changes in care for the ELBW infant occurred over the study period. One significant change was the use of postnatal steroid therapy for chroniclung disease. Among 3 large neonatal networks (the National Institute of Child Health and Development Neonatal Research Network, VON and the Canadian Neonatal Network), a decline in the use of postnatal steroids began in 1999 [26] and continued after the release of a joint statement from the American Academy of Pediatrics and the Canadian Paediatric Society in 2002 formally recommended against the routine use of dexamethasone for the treatment or prevention of chronic lung disease [27]. At network centers participating in this report, despite a large reduction in the rate of steroid use for chronic lung disease over the study period, neither the rate of severe disability nor the rate of cerebral palsy changed. Future work will evaluate how this and other changes in practice and outcomes are associated with the rates of morbidities, such as cognitive delay or cerebral palsy, which contribute to severe disability and will likely extend the length of the follow-up period.

Reporting outcomes based on birth weight alone is limited. Physicians and parents planning for the birth of extremely preterm infants (infants born less than 28 weeks gestation) require reliable outcome information based on both birth weight and gestational age [28]. However, expanding follow-up to include all extremely preterm infants, while also targeting uniform center reporting of comprehensive outcome data for $100 \%$ of eligible infants, may be costly and impracticable to achieve. We believe a simplified structured and standardized followup assessment tool, administered by a personal or phone interview, could identify children with severe disability $[29,30]$. Given such a tool, we speculate that pragmatic and timely outcome data for large numbers of ELBW and extremely preterm infants could be achieved.

Based on the present results, it is possible to create a voluntary, low-cost, pragmatic system of collecting, reporting and monitoring health and developmental outcome that provides both center-based and cohort-based 
insight into the status of surviving ELBW infants in a variety of settings. These infants are at high risk for poor outcome at 18-24 months' corrected age, with death and severe disability remaining highest among infants of the lowest birth weights. Further study will be needed to understand the characteristics predictive of severe disability and the effect of the quality of follow-up care for this population of high-risk infants.

\section{Appendix}

Participating Hospitals, Center Investigator(s) and Project Coordinator(s)

Akron Children's Hospital, Akron, Ohio: John Duby, MD, Diane Langkamp, MD (center investigators), Judy Ohlinger, RNC, MSN (project coordinator); Aultman Hospital, Canton, Ohio: Martha Magoon, MD (center investigator), Kim Reese, BA (project coordinator); Children's Hospital and Clinics, Minneapolis, Minn.: Ronald Hoekstra, MD (center investigator), Sam Olsen, Stacy Svobodny (project coordinators); Children's Hospital of Iowa, Iowa City, Iowa: Michael Acarregui, MD (center investigator), Diane Eastman, ARNP, MA, CPNP (project coordinator); Children's Hospital of Wisconsin, Milwaukee, Wisc.: Laurel Bear, MD (center investigator); Children's of Orange County, Orange, Calif.: Sudeep Kukreja, MD (center investigator), Dini Baker, RN (project coordinator); Children's Hospital of Illinois at Order of St. Francis, St. Francis Medical Center, Peoria, Ill.: Howard Cohen, MD, Connie McConnell (center investigators), Karen Miles (project coordinator); Deaconess Medical Center, Spokane, Wash.: Kathleen Webb, MD (center investigator), Jenni Albert (project coordinator ); DeVos Children's/Spectrum Health, Grand Rapids, Mich.: Benedict Doctor, MD (center investigator), Marcia Gebben, RN, MS (project coordinator); Encino Tarzana Regional Medical Center, Tarzana, Calif.: James L. Banks, MD, Hsiang-Fen F. Su, MD (center investigators); Evanston Hospital, Evanston, Ill.: Joanne Bregman, $\mathrm{PhD}$ (center investigator), Sue Wolf, RN (project coordinator); Good Samaritan Hospital, Cincinnati, Ohio: Kathy Wedig, MD (center investigator); Henry Ford Hospital, Detroit, Mich.: Sudhakar Ezhuthachan, MD, DCH, FAAP, Savitri Kumar, $\mathrm{MD}, \mathrm{DCH}, \mathrm{FAAP}$ (center investigators), Elaine Mondt, CNS, CNNP (project coordinator); IWK Health Centre, Halifax, N.S., Canada: Michael Vincer, MD (center investigator); KK Women's and Children's Hospital, Singapore, Singapore: Poh Choo Khoo, MBChB, MRCP, MRCPCH, FAMS (PAEDS) (center investigator); Legacy Emanual Children's Hospital, Portland, Oreg.: Rebecca E. Mischel, MD (center investigator), Nancy Dolphin, RN (project coordinator); Lenox Hill Hospital, New York, N.Y.: Annamarie Greco, MD (center investigator); Mercy San Juan Medical Center, Carmichael, Calif.: Robert Kahle, MD (center investigator); Monmouth Medical Center, Long Branch, N.J.: Susan Hudome, MD (center investigator), Gwen Wagnon, RN, CPNP (project coordinator); New Hanover Regional Medical Center, Wilmington, N.C.: Robert D. McArtor, MD, Donna R. Vaught, PhD (center investigators), Jane E. Ranney, PhD (project coordinator); Oakwood Hospital and Medical Center, Dearborn, Mich.: Joanna C. Beachy, $\mathrm{MD}, \mathrm{PhD}$ (center investigator); Presbyterian-St. Luke's Medical Center, Denver, Colo.: Delphine Eichorst, MD (center investiga- tor), Laurie Cooper (project coordinator); Rainbow Babies and Children's Hospital, Cleveland, Ohio: Deanne Wilson-Costello, MD (center investigator), Bonnie Siner, RN (project coordinator); Rockford Memorial Hospital, Rockford, Ill.: Patrician Ittmann, DO (center investigator), Sue Wilke, MSEd (project coordinator); St. Barnabas Medical Center, Livingston, N.J.: Teresa Stec, MD (center investigator), Deborah Cialfi, RN, BSN (project coordinator); St. John's Hospital and Medical Center, Detroit, Mich.: John Adams, MD, Maria Duenas, MD (center investigators), Denise Braga, RN (project coordinator); St. John's Mercy Medical Center, St. Louis, Mo.: Gary Dreyer, MD (center investigator), Mary Hackworth, RN (project coordinator); St. Joseph Hospital-Marshfield Clinic, Marshfield, Wisc.: George Hoehn, MD (center investigator), Laurie Weber, RN, BSN (project coordinator); Sunnybrook Health Sciences Centre, Toronto, Ont., Canada: Michael Dunn, MD, FRCPC (center investigator), Elizabeth Asztalos, MD, FRCPC, MSc (project coordinator); Thomas Jefferson University Hospital, Philadelphia, Pa.: Shobhana A. Desai, MD, Marcy J. Gringlas, PhD (center investigators), Christian S Stanley, MSN, CRNP (project coordinator); University of Massachusetts Memorial Health Care, Worcester, Mass.: Francis Bednarek, MD (center investigator), Beth Powers, RN (project coordinator); University of California at San Francisco Medical Center, San Francisco, Calif.: Carol Leonard, PhD, Robert Piecuch, MD (center investigators); University Kebangsaan Malaysia, Kuala Lumpur, Malaysia: Juriza Ismail, MD, Vijayalakshmi C. Ratnam, MSc (center investigators), Ros Azlin Ahmad, BSc (project coordinator); Wheaton Franciscan Healthcare: St. Joseph, Milwaukee, Wisc.: Jeffrey Garland, MD, SM (center investigator), Anne Weinfurter, RN, BSN (project coordinator); Women's Hospital of Greensboro, Greensboro, N.C.: J. Laurence Ransom, MD (center investigator), Kathryn Aldridge, MEd (project coordinator).

\section{Acknowledgements}

This work was supported in part by NIH grant M01RR00109.

We thank the team members at the 33 North American centers and the 3 centers outside North America for their voluntary participation in the VON ELBW Infant Follow-Up Project that made this research possible.

We thank the ELBW Infant Follow-Up Study Group Steering Committee; Howard Cohen, MD (2000-2006), Michael Dunn, MD (2000-2006), Maureen Hack, MD (2000-2002), and Martha Magoon, MD (2000-2006), for contributing to the development, initiation and maintenance of the project; Pete Warner, MS, for information technology support; and Jeanette Conner, $\mathrm{PhD}, \mathrm{MS}$, and Daniel Morris for initial project support and coordination. 


\section{References}

$D_{1}$ The Investigators of the Vermont-Oxford Trials Network Database Project: The Vermont-Oxford Trials Network: very low birth weight outcomes for 1990. Pediatrics 1993; 91:540-545.

-2 Horbar JD, Badger GJ, Lewit EM, Rogowski J, Shiono P: Hospital and patient characteristics associated with variation in 28-day mortality rates for very low birth weight infants. Vermont Oxford Network. Pediatrics 1997;99:149-156.

\3 Horbar JD, Badger GJ, Carpenter JH, Fanaroff AA, Kilpatrick S, LaCorte M, Phibbs R, Soll R, Members of the Vermont Oxford Network: Trends in mortality and morbidity for very low birth weight infants, 1991-1999. Pediatrics 2002;110:143-151.

4 Vohr BR, Wright LL, Dusick AM, Mele L, Verter J, Steichen JJ, Simon NP, Wilson DC, Broyles S, Bauer CR, Delaney-Black V, Yolton KA, Fleisher BE, Papile LA, Kaplan MD: Neurodevelopmental and functional outcomes of extremely low birth weight infants in the National Institute of Child Health and Human Development Neonatal Research Network, 1993-1994. Pediatrics 2000;105: 1216-1226.

5 Hintz SR, Kendrick DE, Vohr BR, Poole WK, Higgins RD, National Institute of Child Health and Human Development Neonatal Research Network: Changes in neurodevelopmental outcomes at 18 to 22 months' corrected age among infants of less than 25 weeks' gestational age born in 1993-1999. Pediatrics 2005;115:1645-1651.

-6 Wood NS, Marlow N, Costeloe K, Gibson AT, Wilkinson AR: Neurologic and developmental disability after extremely preterm birth. EPICure Study Group. N Engl J Med 2000;343:378-384.

7 Costeloe K, Hennessy E, Gibson AT, Marlow N, Wilkinson AR: The EPICure study: outcomes to discharge from hospital for infants born at the threshold of viability. Pediatrics 2000;106:659-671.

8 Tommiska V, Heinonen K, Kero P, Pokela ML, Tammela O, Järvenpää AL, Salokorpi T, Virtanen M, Fellman V: A national two year follow up study of extremely low birthweight infants born in 1996-1997. Arch Dis Child Fetal Neonatal Ed 2003;88:F29-F35.
9 Doyle LW, Victorian Infant Collaborative Study Group: Evaluation of neonatal intensive care for extremely low birth weight infants in Victoria over two decades. I. Effectiveness. Pediatrics 2004;113:505-509.

10 Fily A, Pierrat V, Delporte V, Breart G, Truffert P, EPIPAGE Nord-Pas-de-Calais Study Group: Factors associated with neurodevelopmental outcome at 2 years after very preterm birth: the population-based NordPas-de-Calais EPIPAGE cohort. Pediatrics 2006;117:357-366

11 Bayley N: Bayley Scales of Infant Development-II. San Antonio, Psychological Corp. 1993.

12 Agarwal P, Lim SB: Long-term follow-up and outcome of extremely-low-birth-weight (ELBW) infants. Ann Acad Med Singapore 2003;32:346-353.

13 Vermont Oxford Network Extremely Low Birth Weight Infant Follow-Up Project Manual of Operations, Release 5.0. Burlington, Vermont Oxford Network, 1998.

14 National Center for Health Statistics. CDC Growth Charts: United States. The Percentile Data Files with LMS Values Page. http:// www.cdc.gov/nchs/about/major/nhanes/ growthcharts/datafiles.htm (accessed October 29, 2008).

15 Schmidt B, Davis P, Moddemann D, Ohlsson A, Roberts RS, Saigal S, Solimano A, Vincer M, Wright LL, Trial of Indomethacin Prophylaxis in Preterms Investigators: Longterm effects of indomethacin prophylaxis in extremely-low-birth-weight infants. N Engl J Med 2001;344:1966-1972.

16 Vermont Oxford Network Database Manual of Operations: Release 6.0. Burlington, Vermont Oxford Network, 2001.

17 McDonald H, American Academy of Pediatrics, Committee on Fetus and Newborn: Perinatal care at the threshold of viability. Pediatrics 2002;110:1024-1027.

18 American Academy of Pediatrics, Committee on Fetus and Newborn: Noninitiation or withdrawal of intensive care for high-risk newborns. Pediatrics 2007;119:401-403.

19 Rüdiger M, Iffländer S, Reichert J, Bätzel C, Reiter G, Wauer RR: Which information will be given to parents of preterm infants - a comparison of estimates and local data. J Perinat Med 2007;35:436-442.
20 Wariyar UK, Richmond S: Morbidity and preterm delivery: importance of $100 \%$ follow-up. Lancet 1989;1:387-388.

-21 Wolke D, Söhne B, Ohrt B, Riegel K: Followup of preterm children: important to document dropouts. Lancet 1995;345:447.

22 Callanan C, Doyle L, Rickards A, Kelly E, Ford G, Davis N: Children followed with difficulty: how do they differ? J Paediatr Child Health 2001;37:152-156.

23 Catlett AT, Thompson RJ Jr, Johndrow DA, Boshkoff MR: Risk status for dropping out of developmental followup for very low birth weight infants. Public Health Rep 1993;108: 589-594.

-24 Aylward GP, Hatcher RP, Stripp B, Gustafson NF, Leavitt LA: Who goes and who stays: subject loss in a multicenter, longitudinal follow-up study. J Dev Behav Pediatr 1985;6: 3-8.

25 Castro L, Yolton K, Haberman B, Roberto N, Hansen N, Ambalavanan N, Vohr BR, Donovan EF: Bias in reported neurodevelopmental outcomes among extremely low birth weight survivors. Pediatrics 2004;114:404410.

26 Walsh MC, Yao Q, Horbar JD, Carpenter JH, Lee SK, Ohlsson A: Changes in the use of postnatal steroids for bronchopulmonary dysplasia in 3 large neonatal networks. Pediatrics 2006;118:e1328-e1335.

27 Committee on Fetus and Newborn: Postnatal corticosteroids to treat or prevent chronic lung disease in preterm infants. Pediatrics 2002;109:330-338.

28 Bolisetty S, Bajuk B, Me A-L, Vincent T, Sutton L, Lui K: Preterm outcome table (POT): a simple tool to aid counseling parents of very preterm infants. Aust N Z J Obstet Gynaecol 2006;46:189-192.

29 Pritchard MA, Colditz PB, Beller EM, Queensland Optimising Preterm Infant Outcomes Group: Parents' evaluation of developmental status in children born with a birthweight of $1,250 \mathrm{~g}$ or less. J Paediatr Child Health 2005;41:191-196.

$>30$ Fooks J: Four key questions that identify severe disability. Arch Dis Child 1999;80:6768. 
Errors occurred in the following article: Mercier CE, Dunn MS, Ferrelli KR, Howard DB, Soll RF, and the Vermont Oxford Network ELBW Infant Follow-Up Study Group: Neurodevelopmental outcome of extremely low birth weight infants from the Vermont Oxford Network: 1998-2003. Neonatology 2010;97:329-338 (DOI: 10.1159/000260136).

On page 334 in table 3, in the column 1 for 'Characteristics', 'Apgar at $5 \mathrm{~min} \leq 3$ ' should not have been included as this variable did not reach significance at the $\mathrm{p}<0.001$ level. The text corresponding to table 3 should have read 'Adjusting for the clustering of infants within centers, characteristics associated with an increased risk of severe disability were cystic periventricular leukomalacia, congenital malformation, severe intraventricular hemorrhage, severe ROP or surgery for ROP, oxygen at 36 weeks' postmenstrual age, caregiver education level of high school or less, male gender, delivery room cardiac compressions, and decreasing birth weight per 100-gram interval.'

On page 335 in table 5 , the values for ' $25^{+0}-25^{+6}$ ' and 'Total' in column 1 (bottom two lines) should read '261/698 (37.4)' and '618/1,458 (42.4)' in column 5.

Tables 3 and 5 , as they should have read, are shown:

Table 3. Multivariate logistic regression-adjusted risk factors for severe disability ${ }^{1}$

\begin{tabular}{llll}
\hline Characteristics & OR & \multicolumn{2}{c}{$95 \%$ CI } \\
\hline Cystic PVL & 5.56 & 3.76 & 8.22 \\
Congenital malformation & 3.15 & 1.55 & 6.40 \\
Severe IVH & 3.05 & 2.45 & 3.79 \\
Severe ROP or surgery for ROP & 1.59 & 1.23 & 2.04 \\
Oxygen at 36 weeks & 1.53 & 1.28 & 1.84 \\
Care giver education high school or less & 1.49 & 1.27 & 1.75 \\
Male gender & 1.82 & 1.50 & 2.22 \\
Delivery room cardiac compressions & 1.83 & 1.49 & 2.25 \\
Birth weight per decrease of 100-gram interval & 1.26 & 1.17 & 1.36 \\
\hline
\end{tabular}

$\mathrm{p}<0.001$ for all variables. Max. rescaled $\mathrm{r}^{2}=0.21$. PVL $=$ Periventricular leukomalacia; IVH = intraventricular hemorrhage.

${ }^{1}$ Adjusted for clustering of infants within centers and other factors in the model.

Table 5. Death or severe disability by week of gestational age at birth interval for infants born $<23^{+0}$ to $25^{+6}$ weeks gestation

\begin{tabular}{lrrrr}
\hline $\begin{array}{l}\text { Gestational age } \\
\text { weeks }\end{array}$ & Born & Died & $\begin{array}{l}\text { Of known living infants, } \\
\text { those assessed }\end{array}$ & $\begin{array}{l}\text { Of assessed infants, } \\
\text { those with severe disability }\end{array}$ \\
\hline$<23^{+0}$ & 528 & $504(95.5)$ & $15 / 21(71.4)$ & $11 / 15(73.3)$ \\
$23^{+0}-23^{+6}$ & 916 & $567(61.9)$ & $214 / 298(71.8)$ & $112 / 214(52.3)$ \\
$24^{+0}-24^{+6}$ & 1,452 & $535(36.8)$ & $531 / 737(72.0)$ & $234 / 531(44.1)$ \\
$25^{+0}-25^{+6}$ & 1,581 & $371(23.5)$ & $698 / 965(72.3)$ & $261 / 698(37.4)$ \\
\hline Total & 4,477 & $1,977(44.2)$ & $1,458 / 2,021(72.1)$ & $618 / 1,458(42.4)$ \\
\hline
\end{tabular}

Figures in parentheses represent percentages. 